\title{
TASMOLA KURGANS IN AIYRTAS VALLEY IN CENTRAL KAZAKHSTAN
}

\author{
Arman Z. Beisenov \\ Research Center for the History and Archeology of Begazy-Tasmola, Almaty, Republic of Kazakhstan
}

\section{Darkhan T. Shashenov}

Karaganda Regional Museum of Local History, Karaganda, Republic of Kazakhstan

\begin{abstract}
The report introduces study materials of new kurgans dating back to the early Iron Age of Central Kazakhstan. Monuments are located in the eastern part of the Karaganda region. Geographically, this territory is part of the Kazakh Upland's eastern region. In three cemeteries located at the area of Mount Aiyrtas, 8 kurgans were excavated. Mounds of 5-13 $\mathrm{m}$ in diameter and $0.2-1.2 \mathrm{~m}$ tall are built of earth and stone. Each mound contains one grave. Dead bodies are placed head to the northwest. Despite the fact the kurgans were heavily robbed, the data about the funeral rite demonstrate important aspects of the of the ancient population culture of this region, as well as the found objects do. According to archaeological data, the monuments belong to the Tasmola culture of the Saka tribes time period. The materials obtained indicate that representatives of the ordinary population are buried at the studied sites. Monuments are dating back to VII-V centuries BC. The study of monuments left by the lower class is a poorly researched aspect of tasmol culture's population, so it is very important. The data accumulated by now have been obtained from burials being widely scattered over a large area. Studying small mounds in places of their accumulation is more promising, though. One of such places is Aiyrtas valley, where large number of small mounds is located, as parts of nearby cemeteries. There are still some unexcavated kurgans in Aiyrtas-2 kurgan cemetery remaining. As it is known, a complete study of burial grounds makes it possible to draw more substantiated conclusions about the social structure of ancient society. There are other burial grounds in the area, including elite kurgans.
\end{abstract}

Key words: Central Kazakhstan, Tasmola culture, barrow, kurgan, funeral rite.

Citation. Beisenov A.Z., Shashenov D.T., 2020. Tasmola Kurgans in Aiyrtas Valley in Central Kazakhstan. The Lower Volga Archaeological Bulletin, vol. 19, no. 1, pp. 268-284. (in Russian). DOI: https://doi.org/10.15688/ nav.jvolsu.2020.1.15

\section{ТАСМОЛИНСКИЕ КУРГАНЫ В УРОЧИЩЕ АЙЫРТАС В ЦЕНТРАЛЬНОМ КАЗАХСТАНЕ}

\section{Арман Зияденович Бейсенов}

Научно-исследовательский центр истории и археологии Бегазы-Тасмола, г. Алматы, Республика Казахстан

\section{Дархан Тастемирович Шашенов}

Карагандинский областной историко-краеведческий музей, г. Караганда, Республика Казахстан

Аннотация. В сообщении вводятся в научный оборот материалы изучения новых курганных захоронений раннего железного века из Центрального Казахстана. Памятники находятся на территории восточной части Карагандинской области. В географическом отношении она входит в черту восточного крыла Казахского мелкосопочника. В районе горы Айыртас в составе трех могильников было раскопано всего 8 курганов. Насыпи диаметром 5-13 м и высотой 0,2-1,2 м сооружены из земли и камня. Каждая насыпь содержит одну 
могилу. Умершие люди были уложены головой на северо-запад. Курганы сильно ограблены, тем не менее данные погребального обряда, а также найденные вещи демонстрируют важные стороны культуры древнего населения этого региона. Судя по археологическим данным, памятники относятся к тасмолинской культуре сакского времени. Полученные материалы позволяют считать, что изученные захоронения оставлены представителями рядового населения. Дата памятников - VII-V вв. до н.э. Актуальность исследования памятников низших слоев населения тасмолинской культуры обусловлена их малоизученностью. Накопленные к настоящему времени данные были получены из захоронений, которые сильно разбросаны на большой территории. Более перспективным является изучение малых насыпей в районах их концентрации. Одним из таких пунктов является долина Айыртас, где имеется значительное число малых насыпей в составе близлежащих могильников. В могильнике Айыртас-2 имеются еще не раскопанные курганы. Как известно, полное исследование могильников дает возможность получения более обоснованных выводов по социальному строю древнего общества. Также в данном округе расположены и другие могильники, в том числе и группы из элитных курганов.

Ключевые слова: Центральный Казахстан, тасмолинская культура, курган, могильник, погребальный обряд.

Цитирование. Бейсенов А. З., Шашенов Д. Т., 2020. Тасмолинские курганы в урочище Айыртас в Центральном Казахстане // Нижневолжский археологический вестник. Т. 19, № 1. С. 268-284. DOI: https:// doi.org/10.15688/nav.jvolsu.2020.1.15

\section{Введение}

Гора Айыртас, в районе которой проводились археологические исследования, находится на территории Каркаралинского района Карагандинской области. «Айыр» на казахском языке означает нечто раздвоенное, расходящееся (например, вилы). Для каменистого ландшафта Казахского мелкосопочника, изобилущего весьма разными поднятиями в рельефе, это выражение часто указыает на возвышенность, которая имеет посредине некую седловинку или же несколько таковых. Айыртас - буквально «раздвоенный камень», то есть гора, имеющая таковой облик при взгляде со стороны.

Возвышенность вытянута с северо-запада на юго-восток, общей длиной около 8 км. Северо-западная часть хребта более занижена. Наиболее высокая точка расположена в юго-восточной части хребта, абсолютная высота ее - 1009 м (по данным топокарты, квадрат М43-XXIII). Возвышенность характеризуется, особенно в высокой части, довольно крутыми склонами, густо изрезанными балками. Хорошо просматриваются многочисленные выходы коренных пород. Карбоновые породы, из которых сложены горы, перекрыты элювиально-делювиальными отложениями. Каштановые почвы покрыты разнотравной степной растительностью, где преобладают полынно-типчаковые сообщества. Много здесь зарослей степной караганы [Ка- раганда ..., 1986, с. 92]. Преимущественно с северной, северо-восточной, а также восточной стороны горы расположены значительные равнинные пространства. С запада и юга рельеф более холмисто-гористый. Всю эту местность запада, севера и востока окаймляют русла степных рек. Это довольно известная и значимая для ландшафта востока Казахского мелкосопочника р. Тундик, протекающая к западу от горы Айыртас в северо-восточном направлении, а также река Айгыржал, текущая с юго-востока и впадающая в р. Тундик, являясь ее правым притоком. По отношению к р. Тундик рассматриваемая округа входит в районы ее верхнего течения.

В долине Айыртас начиная с 2007 г. осуществлялись кратковременные разведочные поездки, хотя о полном осмотре всей местности нельзя сказать. В 2014, 2019 гг. археологической экспедицией Карагандинского областного историко-краеведческого музея здесь были исследованы курганы раннего железного века в составе трех могильников Айыртас-1, Айыртас-2 и Естек ${ }^{1}$, материалы которых приводятся в данной публикации. Изученные памятники относятся к тасмолинской культуре Центрального Казахстана [Beisenov et al., 2016].

Два черепа из ранее вскрытых курганов из могильников Айыртас-1 и Естек были изучены антропологами и опубликованы [Бейсенов и др., 2015]. В настоящее время, после работ 2019 г., подготовлены новые палеоант- 
ропологические материалы из вновь раскопанных курганов, в том числе три полных скелета, включая черепа, а также отобраны образцы для выполнения радиоуглеродного анализа. Планируется продолжение исследований.

\section{Материалы}

Три изученных могильника находятся к востоку, северо-востоку и югу от горы Айыртас. В северо-западной части хребта, на восточном склоне расположена одноименная действующая зимовка (ферма), возле которой базировался экспедиционный лагерь в полевых сезонах 2014 и 2019 годов. На расстоянии 2 км восточнее от этой зимовки находится могильник Айыртас-1. В 7 км к северо-востоку от зимовки расположен могильник Айыртас-2. Третий могильник - Естек, находится к югу от хребта, в непосредственной близости от одноименной зимовки. Расстояние от зимовки Айыртас до этого пункта 8 км (рис. 1,1 ).

Всего в трех могильниках к настоящему моменту раскопаны восемь курганов. Айыртас-1 и Естек, состоящие каждый из двух курганов, исследованы полностью. Из девяти курганов могильника Айыртас-2 раскопкам подверглись четыре. Основные данные погребального обряда исследованных памятников показаны в таблице 1.

Изученные памятники обладают целым рядом общих свойств. Их суть в следующем.

Насыпи имеют округлую форму и смешанное, каменно-земляное, содержание. Под каждой насыпью находится одна могила, что в принципе характерно для тасмолинской культуры. Тип могил - грунтовая яма. Все они не имеют перекрытий. Их глубина небольшая, около 1 м, лишь в одном случае, в кург. 2 могильника Естек, достигает 1,4м. В шести случаях могилы ориентированы по линии С3-ЮВ. В кург. 5 могильника Айыртас-2 могила ориентирована по линии ЮЗ-СВ. Могила кург. 1 могильника Естек имеет ориентировку по линии 3-В. Положение костяка определено в шести случаях - вытянуто, на спине. Ориентировка погребенных определена также в шести случаях. За исключением кург. 5 могильника Айыртас-2, где выявлена северовосточная ориентировка костяка, в пяти кур- ганах умерших укладывали головой на С3. В двух остальных курганах, где ориентировка костяка не определена, могилы длинной осью ориентированы по линиям С3-ЮВ (кург. 2 могильника Айыртас-1), 3-В (кург. 1 могильника Естек). Наиболее вероятной для этих курганов является северо-западная и западная ориентировка умерших.

В заполнении могил камни находятся в верхнем слое - преимущественно до глубины 15-25 см от уровня древней поверхности. Ниже залегает грунтовый слой, в который попали разноразмерные камни в процессе ограбления могилы. В ходе раскопок вокруг могил зафиксированы небрежно сложенные каменные набросы, поверх которых залегают слои смешанного, каменно-земляного состава.

Судя по убедительным признакам, ограблены пять курганов из восьми. Тем не менее их общий характер в целом улавливается. На относительно ровной, слегка подчищенной поверхности выкапывали могилу, которую потом заполняли вынутым материковым грунтом. Затем на засыпанную могилу укладывался каменный слой - наброс округло-овальный в плане формы, внешние контуры которого выходили за пределы погребальной камеры со всех сторон. В процессе оседания грунта внутри могилы камни этого наброса, также оседая, занимали верхний слой заполения. Вместе с тем в некоторых случаях камни в могилу, возможно, укладывались уже в ходе заполнения. Об этом свидетельствуют особенности заполнения могилы в кург. 2 могильника Естек, где зафиксирована наибольшая глубина захоронения. Здесь удалось заметить, что грабители проникли в могилу со стороны изголовья, вскрыв при этом значительную площадь погребальной камеры. Нетронутым остался сектор заполнения в юговосточном углу, где в момент раскопок хорошо фиксировался довольно плотный верхний каменный слой, мощностью до 35 см. На невысокий каменный холмик над могилой в дальнейшем набрасывали землю вперемежку с камнем. Крепида выявлена в двух курганах среди раскопанной серии: на кург. 1 могильника Айыртас, который имеет, кстати, наибольшие размеры насыпи, и кург. 2 могильника Естек. Ограды и рвы на исследованных курганах отсутствуют. 
Среди неисследованных памятников могильника Айыртас-2 крепида насыпи, а также ограда и ров фиксируются на кургане 4. Это наибольший по своим параметрам курган во всех трех могильниках. Его исследование намечено на ближайшие годы.

В ходе ограбления заметно пострадали насыпи. Некоторая практика исследования подобных курганов в Центральном Казахстане позволяет предположить, что вскрывали курганы еще в древности. В ходе поздних ограблений, как, например, в результате деятельности «бугровщиков», обычно вскрывали значительную площадь в центре насыпи, открывали всю могилу. На других курганах имеются интенсивные следы выборки камней на кург. 2 могильника Айыртас-1 и особенно на кург. 9 могильника Айыртас-2.

Могильник Айыртас-1, исследованный в 2014 г., состоит из двух курганов, расположенных по линии север-юг.

Курган 1. Северный в группе, является самым крупным среди всех изученных объектов. Округлой формы крепида из довольно крупных, длиной до 35 см, обломков плитняка проложена вплотную к насыпи, некоторые секторы ее просматривались еще до раскопок. В заполнении могилы с глубины 0,4 м от уровня древней поверхности были найдены череп и другие кости от человеческого скелета, в том числе одна бедренная кость, целые и фрагментированные ребра, спинные позвонки, мелкие кости кистей рук. Череп лежал затылочной частью вверх в центральной части могилы, на 0,35 м выше дна. На дне могилы расчищены одна бедренная кость, четыре позвонка, лежащие в анатомическом порядке. По этим костям ориентировка погребенного определяется достаточно ясно - головой на С3. В юговосточной части могилы, на уровне $25-30$ см выше дна, найдены два однотипных кольца, свернутые из полосы золотого листа (рис. 2,1); бронзовый черешковый трехлопастной наконечник стрелы (рис. 2,2); фрагмент, по-видимому, чумбура, сплетенного из овечьей пряжи (рис. 2,3). Размеры колец: диаметр 1,9 см, ширина полосы 0,9 см, толщина полосы около 1,5 мм. Общая длина наконечника 5 см, боевой головки 2,3 cм, черешка, соответственно, 2,7 см. Нижняя часть округлого у основания черешка уплощена. Диаметр основания 4 мм, ширина плоского конца 6 мм. Край одной лопасти поврежден, воможно при ограблении захоронения. Для территории всего Казахстана и за его пределами подобные наконечники характерны для раннесакской эпохи. Аркан из сплетенной пряжи диаметром около 6-7 мм при сохранившейся длине около 5 см мог также служить поясом для штанов, как в этнографическое время, или использоваться таким же образом для верхней одежды.

На расстоянии 6 м к юго-западу от рассмотренного кургана находится каменная выкладка диаметром около 3 м при высоте 0,1 метра. Камни небольших размеров уложены плотно, покрывая всю площадь сооружения. Раскопки не выявили каких-либо ям, пятен, находок.

Курган 2. Верх насыпи сильно потревожен, зафиксированная при раскопках высота вряд ли является первоначальной. Вся поверхность насыпи густо проросла кустарником, центральная часть занижена в результате ограбления. В заполнении могилы найдены череп и отдельные разрозненные кости от человеческого скелета. Находок нет.

Могильник Айыртас-2 исследовался в 2019 году. Он включает в себя (рис. 1,2) всего девять курганов, расположенных цепочкой по линии ЮЗ-СВ. Центральное место в цепочке занимает неисследованный кург. 4. Диаметр каменно-земляной насыпи 20 м, высота 0,9 метра. Просматриваются участки крепиды из крупных плит. На расстоянии 1 м от полы насыпи вкруговую устроена ограда из плашмя уложенных крупных плит. Диаметр ограды 22 метра. Еще далее, на расстоянии 0,50,6 м, находится ров, сильно оплывший. Наибольшая ширина рва на современной дневной поверхности свыше 2 метров. Наибольшая глубина - в северо-западном секторе 0,3 метра. Таким образом, этот памятник имеет все основные признаки, более характерные для курганов раннего этапа тасмолинской культуры: крепиду, ограду и ров.

Планиграфия Айыртас-2 показывает, что основу ансамбля составляют насыпи, образующие более правильную линию в цепочке, тогда как кург. 5 и 6 сооружены вне цепочки. Определение хронологии этих двух объектов затруднено ввиду остутствия более или менее надежно датирующих вещей. На этом 
могильнике всего раскопано четыре захоронения в кург. 5, 6, 8 и 9.

На дне могильной ямы кург. 5 находился скелет человека (табл. 1), кости в анатомическом порядке, череп слегка повернут вправо. Ниже правой кисти найдены многочисленные, расположенные бессистемно, фрагменты от железных изделий. Относительно крупными оказались свыше 10 фрагментов, остальные представляли собой мелкие расслоившиеся куски корродированного металла, лежавшие в слое коричневой трухи. Сохранившиеся крупные фрагменты имеют клиновидное сечение. По-видимому, в могилу были положены два крупных ножа (рис. 2,4,5). Предполагаемая длина первого около $30 \mathrm{~cm}$, наибольшая ширина фрагментов $2,5 \mathrm{~cm}$, толщина 0,9 см. Второй, возможно, имел длину свыше $20 \mathrm{~cm}$, наибольшая ширина фрагментов около 2 см, толщина 0,7 см. В районе правого локтя, на 5 см выше дна могилы найдено полое изделие, свернутое из бронзового листа (рис. 3,4). Один конец предмета заужен. Диаметр широкого конца 9 мм, узкого - 6 мм. Внутренние диаметры, соответственно, - 6 и 3 мм. Толщина листа около 1,5 мм. Функция предмета неясна. Это единственный курган среди изученной серии, где умерший уложен головой на СВ. Такая ориентировка костяка в целом не характерна для тасмолинской культуры.

Курган 6 сильно ограблен. В могиле, на глубине 0,9 м, расчищена лопатка лошади, лежавшая поперек длинной оси ямы. Ниже на 0,3 м, на дне могилы, в непотревоженном виде сохранились лишь обе берцовые кости погребенного. Судя по размерам костей, это захоронение подростка. Находок нет.

Насыпь кург. 8 сохранилась лучше, чем все другие изученные памятники. Она имеет вид низкого усеченного конуса, камни, более крупные, чем в остальных насыпях, уложены довольно плотно. На дне могилы найден полный скелет человека. Вещей нет.

Курган 9, напротив, представляет собой сооружение, наименее сохранившееся среди всех курганов трех могильников. Вокруг него зафиксировано 10 каменных могил казахского времени, вероятно XIX-XX вв. (рис. 1,2). Несомненно, верхний слой каменной насыпи кургана был разобран для строительства этих могилок. При разборке камней насыпи в северо-восточном секторе найдена каменная зернотерка (рис. 2,6). Изделие длиной $40 \mathrm{~cm}$, шириной 13 см и толщиной $7 \mathrm{~cm}$, выполненное из сиенита, было положено на древний горизонт рабочей поверхностью вверх, на расстоянии 0,7 м от края насыпи. На дне могилы находился полный скелет человека. Возле правого локтя умершего найдены многочисленные мелкие и лежавшие бессистемно фрагменты от железного изделия. Свыше 10 из них относительно определяемы в качестве фрагментов крупного ножа или кинжала. Предполагаемая длина предмета - свыше 20 сантиметров. Сечение фрагментов клиновидное или же уплощенно-овальное. Лишь два фрагмента соединяются между собой, составляя одну часть предмета длиной 6,4 см, шириной $1,8 \mathrm{~cm}$, толщиной около 0,9 см (рис. 3,3). Еще один фрагмент представляет собой не полностью сохранившееся кольцо (рис. 3,2). Диаметр около 4,5-5 сантиметров. Предположительно, в могилу был положен железный кинжал с навершием, оформленным в виде широкого кольца. На правой тазовой кости скелета находился каменный кайрак-точило (рис. 3,1 ) хорошей сохранности, на котором была низкая бронзовая ворворка (рис. 3,5). Длина точила 13,2 см, ширина 2,5 см, толщина 1,4 см, выполнено из мелкозернистого песчаника ${ }^{2}$. Диаметр отверстия для подвешивания: на лицевой стороне 1,1 см, на тыльной $-0,5$ см. Диаметр основания ворворки 1,6 см, высота - 0,5 см. Оба изделия находились в непотревоженном виде. Кайрак находился в «рабочем» положении, то есть отверстием вверх, в сторону пояса умершего. Бронзовое изделие, служившее деталью крепления точила к поясу, лежало прямо на отверстии для подвешивания.

Насыпи обоих курганов могильника Естек значительно повреждены. В сильно ограбленной могиле кург. 1, преимущественно в нижней части заполнения, найдены отдельные разрозненные кости человеческого скелета. Вещей нет. На расстоянии 8 м восточнее кургана находится жертвенник, имеющий вид сплошной каменной вымостки округлой формы. Его диаметр 6 м, высота 0,1 м. Объект совершенно аналогичен исследованному жертвеннику близ кург. 1 могильника Айыртас-1. Раскопки не выявили каких-либо 
ям, пятен, следов человеческого захоронения, находок.

В кург. 2, в центре насыпи, на 15 см ниже современной поверхности, в заполнении грабительской воронки найдены пять фрагментов круглого бронзового зеркала с петелькой на тыльной стороне (рис. 3,6). Диск диаметром 8,5 см не имеет бортика, толщина 2 мм, размеры полукруглой петельки: длина 1,9 мм, высота 9 мм, ширина 6 мм, толщина 3 мм. На такой же глубине, на расстоянии 1 м восточнее обнаружен один фрагмент керамики (рис. 3,7 ). В заполнении могилы на разных уровнях найдены 10 каменных бус (рис. 3,817). Сведения о них приведены в таблице 2. От человеческого скелета сохранились череп, найденный в северо-западной части могилы, на 20 см выше дна, затем лежавшие на дне в анатомическом порядке кости обеих ног, а также немногочисленные разрозненные кости и их фрагменты, расположенные беспорядочно.

Керамика представлена фрагментом шейки сосуда, изготовленного с помощью гончарного круга. Венчик плоский, отогнутый наружу, ниже расположен сформованный валик, треугольный в разрезе. На переходе от короткой шейки к тулову прочерчена горизонтальная линия с двумя волнистыми линиями под ней. Толщина стенок $0,7-0,8$ см. Исходное сырье - сильноожелезненная среднепластичная глина с естественной примесью кварцевого песка; формовочная масса состоит из глины без искусственных минеральных добавок. Сосуд обжигался в окислительной среде при температуре не менее $900{ }^{\circ} \mathrm{C}$, после чего подвергался чернению с кратковременной выдержкой в восстановительной атмосфере. В результате обе поверхности получили черную окраску ${ }^{3}$.

Согласно полученным данным, все изученные курганы являются местами захоронения предствителей рядового населения. Хотя полное обследование всей округи еще предстоит, тем не менее известно, что здесь имеются и крупные курганы. На расстоянии 12 км к востоку от горы Айыртас находится гора Борили (каз. «волчья») с абсолютной высотой 958 м, у подножия которой расположен элитный могильник тасмолинской культуры. Центральную часть этого небольшого могиль- ника, открытого А.З. Бейсеновым в 2007 г., составляют курганы высотой 3-4 метра.

В округе есть казахские мазары и простые захоронения: как глинобитные, так и каменные. Также в ходе кратковременных маршрутов были обнаружены и осмотрены остатки ряда казахских зимовок. В 10 км севернее Айыртаса находится гора под названием Ешкиолмес (каз. «не погибнут и козы»), с абсолютной высотой 1034 м. Такое название в старину казахи присваивали урочищам, которые считались особо удобными благодаря отсутствию в зимнее время большого снега. Обычно местные казахские названия неплохо подтверждают особенности расселения скотоводческих общин. Так, архивные данные показали, что в урочище Ешкиолмес находилось зимнее кочевье многолюдного семейства Кусбека Таукина (Букейханова), человека богатого и влиятельного, в середине XIX в. занимавшего в два срока должность старшего султана (Ага-султан) Каркаралинского внешнего округа Западно-Сибирского подчинения [История Каркаралы..., 2009, с. 88]. Изучаемый район будет интересен и для этноархеологических исследований. Отдельной темой можно ставить вопрос о необходимости поиска здесь поселений сакского времени.

\section{Обсуждение материалов}

Среди изученной группы памятников раннюю дату дает кург. 1 в могильнике Айыртас-1, где уцелел бронзовый наконечник стрелы. Черешковые трехлопастные наконечники стрел данного типа в Казахстане известны по меньшей мере с эпохи поздней броны. Как показывают материалы археологических исследований, они бытовали в среде населения бегазы-дандыбаевской культуры, оставившего могильник Бегазы в Центральном Казахстане [Маргулан, 1979 , с. 85 , рис. 55,10$]$. Для памятников раннесакского времени Казахстана исходной территорией распространения бронзовых трехлопастных черешковых наконечников, возможно, следует считать территорию Центрального Казахстана. В начале раннесакской эпохи, в период VIII-VII вв. до н.э., такие наконечники получают распространение в разных регионах Казахстана [Хабдулина, 2017]. Учитывая особенности погребального 
сооружения, погребального обряда в целом, кург. 1, по-видимому, нужно датировать финалом раннесакского времени, в рамках периода VII-VI вв. до н.э. Золотые кольца из этого кургана не имеют аналогов среди имеющихся данных по тасмолинской культуре. Захоронение сильно ограблено, и это не дает возможности связать эти предметы с определенной областью в положении умершего, функция их не ясна. Данные изучения черепа показали, что в кург. 1 могильника Айыртас-1 захоронен мужчина в возрасте 45-55 лет [Бейсенов и др., 2015, с. 27-28, рис. 11].

Все остальные материалы из курганов долины Айыртаса не дают какую-либо узкую дату в рамках существования тасмолинской культуры и предварительно датируются периодом VII-V вв. до н.э.

Железные изделия, в том числе ножи, распространяются в Центральном Казахстане начиная еще с VII в. до н.э. [Кадырбаев, 1966], а скорее в период VIII-VII вв. до н.э. Бытуют они в течение всего времени существования тасмолинской культуры. Согласно общей тенденции распространения изделий из этого металла в сакском мире Казахстана в раннесакское время они еще редки, но в последующий период их количество увеличивается. Выше было высказано предположение о кинжале с кольцевым навершием в кургане 9 могильника Айыртас-2. Определенности здесь, конечно, быть не может. Следует лишь учесть, что в таком случае для этого захоронения VII в. до н.э. надо исключить, так как таковые изделия в памятниках сакского круга, а надо сказать и в других сопредельных регионах, появляются не раньше периода VI$\mathrm{V}$ вв. до н.э.

Возможно, так же обстоит ситуация и с кург. 2 из могильника Естек, где, согласно данным антропологического исследования, была погребена женщина в возрасте 18-25 лет [Бейсенов и др., 2015 , с. $45-46$, рис. 32]. Помимо 10 штук бусин здесь найдено круглое бронзовое зеркало без бортика, с петелькой на тыльной стороне. Изделие представлено в пяти фрагментах: оно было положено разбитым, как это практиковалось в древности, или же это результат действия грабителей - судить трудно. Когда-то бортику зеркал приписывали исключительный хронологический признак, уве- ренно относя его ко второму и последующим этапам сакских культур. Сейчас это не вполне однозначно. Зеркала без бортика, имеющие традиционную петельку на обороте, но несколько уменьшенные, могли появиться и концу раннесакского времени. В этом случае для даты этого кургана также наиболее вероятным будет период не ранее VI в. до н.э. или же конца VII - VI в. до н.э. Фрагмент круговой керамики, найденный в насыпи этого кургана, не входит в предметный комплекс тасмолинской культуры. О дате этого единственного фрагмента судить невозможно, не исключено, что он имеет позднее происхождение.

Каменные зернотерки и их обломки находят повсеместно в памятниках сакского мира Казахстана. В рамках тасмолинской культуры они найдены в насыпях двух курганов и в жертвеннике могильника Нуркен-2 [Бейсенов, 2016], в курганах могильников Акбеит, Назар-2. Помимо этих пяти случаев, касающихся новых исследований в Центральном Казахстане, еще в ранние периоды работ М.К. Кадырбаев нашел зернотерку овальной формы размерами $36 \times 24 \times 5$ см в кургане с «усами» 1 могильника Кийксу. Комплекс состоит из западной, «центральной» насыпи и восточного «малого» кургана, от которого отходят две каменные гряды. Предмет, названный исследователем зернотеркой, был найден в западном кургане, «у верхнего края могильной ямы». Рисунок, приведенный в работе М.К. Кадырбаева [Кадырбаев, 1959, с. 164165 , рис. 1a], напоминает также и плоский каменный жертвенник, хотя обращают на себя внимание его более крупные размеры, чем для обычных экземпляров, которые находят в могилах тасмолинского населения. Более узкая дата Кийксу не определена из-за отсутствия других находок. Курганы с каменными зернотерками в могильниках Нуркен-2, Акбеит, Назар-2 относятся к раннесакскому времени, но, как показывают данные, зернотерки в Центральном Казахстане укладывались также и в насыпи более поздних этапов. Так, в кург. 3 могильника Карамола каменная зернотерка длиной 42 см, шириной 17,8 см, высотой 5,7 см находилась рабочей частью вверх на восточной периферии нижней каменной насыпи. Эту часть наземного сооружения сверху покрывала земляная насыпь, на восточной пе- 
риферии которой находились два сосуда, положенные, как и зернотерка, на древнюю поверхность [Бейсенов, 2014]. В качестве даты изученных курганов карамолинского могильника предложен период IV-III вв. до н.э. А.3. Бейсенов не относит курганы на могильнике Карамола к тасмолинской культуре и, в свою очередь, им было высказано мнение об отнесении их к отдельному типу захоронений сакского круга [Бейсенов, 2014, с. 77]. Это положение показывает, что оставление каменных зернотерок в насыпях курганов, по-видимому, является общей сакской традицией, бытовавшей на большой территории в течение довольно длительного времени. Одним словом, каменная зернотерка в нашем кургане не дает возможности определить узкую дату. На это указывают и материалы соседних регионов, в том числе Саяно-Алтая.

Зернотерки на Саяно-Алтае находят повсеместно в погребальных сооружениях. Две зернотерки обнаружены в кург. 7 могильника Аргалыкты-XIII в Туве [Савинов, 1994]. С этим курганом, относящимся к памятникам шанчигского типа (финал эпохи бронзы, предскифское время) [Кызласов, 1977; Савинов, 2002], связан также оленный камень общеевразийского типа. Курган 1 могильника Ак-Даг I, где найдены зернотерка и курант [Тетерин, Митько, 2014], относится алдыбельской культуре раннескифского времени. В Горном Алтае зернотерки были найдены и в раннескифских курганах, как, например, на могильниках Карбан-1, Кызык-Телань-1, Кор-Кобы-1, Семисарт-1 и в курганах пазырыкского времени [Кирюшин, Тишкин, 1997, с. 58]. Ситуация с зернотерками дополняется также и фактами находок каменных жерновов ручной мельницы, которых в скифо-сакское время тоже оставляли в насыпях курганов [Молодин, Бородовский, 1994; Наглер, 2000].

Предложенная для изученных памятников хронология, надо надеяться, будет уточнена в ходе предстоящих исследований. Помимо раскопок оставшихся курганов, планируется проведение серии радиоуглеродных анализов. Особо актуально это для кург. 5 могильника Айыртас-2, находящегося вне основной линии цепочки. Рядом расположенный кург. 6 (рис. 2) содержал захоронение с северо-западной ориентировкой, характерной для тасмолинской культуры. Курган 5, имевший диаметр всего 5 м и высоту 0,2 м, показал северо-восточную ориентировку костяка, нехарактерную для этой культуры. Плохо сохранившиеся фрагменты железных ножей и бронзовое изделие не дали основания для какойлибо узкой даты. Северо-восточная ориентировка умершего характерна для погребений коргантасского типа. Дата основной массы этих памятников IV-II вв. до н.э., предполагается, что нижняя ее граница может быть удревнена (подробнее о коргантасском типе см.: [Бейсенов, 1995; 2017; Китов, Бейсенов, 2015; Бейсенов, Дуйсенбай, 2015a; 2015б; Шульга, 2015]). Особенности погребального сооружения, тип могилы кургана 5 близки к аналогичным элементам остальных изученных объектов. Кроме того, здесь отсутствует важная деталь обряда коргантасского населения - внутримогильный головной жертвенник с черепами и костями ног домашних животных. В целом кург. 5, возможно, отражает процессы смешения ранних коргантасцев с местными тасмолинскими племенами или же относится к более поздним периодам.

\section{Выводы}

Как показывают природные особенности урочища Айыртас и прилегающих к нему местностей, данные памятников (как раскопанных, так и еще неизученных), а также материалы этнографической современности, представляемый район является перспективным для научных исследований. Здесь издревле имеются хорошие условия для жизни степных скотоводов. Горная возвышенность, при которой находятся удобные равнины, наличие близкорасположенных водотоков в виде рек или же крупных родников - вот основные слагаемые этого удобства для районов востока Казахского мелкосопочника. Некоторая практика работы в этом регионе показала, что на протяжении длительного времени это свойство мелкосопчника определяло основные тенденции расселения скотоводческих общин как в древности, так и в этнографическое время. Изученные здесь в течение двух полевых сезонов восемь курганов датируются в рамках периода VII-V вв. до н.э. Более узкую дату имеет лишь один памятник, а именно 
кург. 1 могильника Айыртас, который может быть отнесен VII-VI вв. до н.э.

Исследование рядовых курганов тасмолинской культуры обусловлено актуальностью, которая создает особую специфику в разработке тасмолинской проблематики. Изученные в период конца 1940-х - 1950-х гг. А.Х. Маргуланом и М.К. Кадырбаевым рядовые курганы представляли собой разрозненные памятники из разных могильников, расположенных достаточно далеко друг от друга [Кадырбаев, 1958; 1959]. Затем в конце 1950-х - начале 1960-х гг. в могильниках на побережье р. Шидерты были открыты погребения воинской элиты, которые сопровождались также и более простыми захоронениями [Кадырбаев, 1966]. Открытые в современную эпоху могильники Талды-2, Карашокы, Назар-2, Шерубай относятся к родоплеменной элите. В Центральном Казахстане эпизодически изучаются одиночные курганы небольших размеров, бескурганные захоронения [Ткачев, Волошин, 2011; Кукушкин, Ломан, 2013], которые пока не дают достаточного объема источников для исследования вопросов, связанных с рядовыми членами общества. Кажущиеся малочисленность и «неуловимость» погребальных сооружений рядового населения тасмолинской культуры связаны с общими особенностями расселения племен этого сообщества. Для этой культуры, занимавшей огромные холмисто-степные пространства Казахского мелкосопочника, характерны: небольшие могильники, часто представленные группами всего из нескольких насыпей; обилие одиночных курганов, чему в принципе соответствует и характер распространения небольших по площади поселений-зимников [Бейсенов и др., 2017]. На фоне эпизодических раскопок сильно разрозненных памятников или вскрытия единичных насыпей из разных могильников однозначно актуальным будет исследование интересующих нас малых курганов в районах той или иной их концентрации. Все три представленные в настоящем сообщении группы находятся неподалеку друг от друга. Все изученные курганы демонстрируют явную близость в элементах погребального сооружения, могил, ориентировке костяков. Обращает внимание наличие небольших жертвенников [Бейсенов, 2015], устраиваемых вблизи кургана, которые характерны также для могильников и одиночных курганов элиты.

\section{ПРИМЕЧАНИЯ}

1 В старину казахи естеками называли башкир. Значительная часть современных ферм восходит к старым казахским зимовкам. Возможно, когда-то здесь жил человек с таким именем. Известно, что в XVIII столетии, особом в истории башкирского народа, отдельные башкирские общины уходили в казахскую степь. Возможна и другая интерпретация. В казахской традиции нередко давались мальчикам имена соседних народов, напр., Узбекали, Кыргызбай, Ногай, Урусхан и др. Точно так же у узбеков и кыргызов в старину бытовало мужское имя Казакбай.

${ }^{2}$ Определение материала зернотерки и точила выполнено д.т.н. В.С. Портновым (Караганда, Казахстан).

${ }^{3}$ Определение выполнено к.и.н. В.Г. Ломаном (Караганда, Казахстан). 
А.З. Бейсенов, Д.Т. Шашенов. Тасмолинские курганы в урочище Айыртас в Центральном Казахстане

\section{ИЛЛЮСТРАЦИИ}
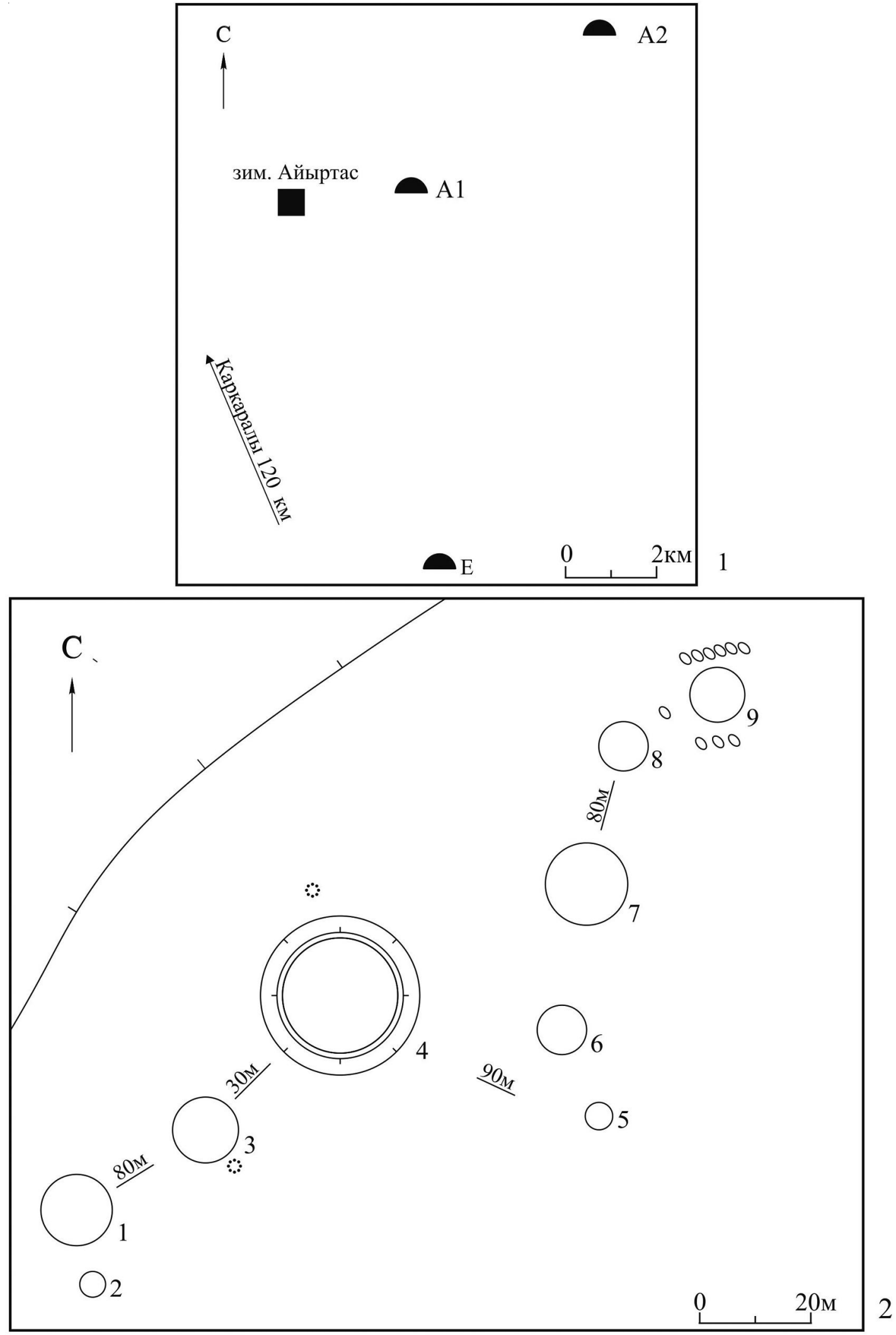

Рис. 1. Расположение могильников Айыртас-1, Айыртас-2 и Естек (1) и план могильника Айыртас-2 (2) Fig. 1. Location of Aiyrtas-1, Aiyrtas-2 and Estek kurgan cemeteries (1) and the Plan of Aiyrtas-2 kurgan cemetery (2) 
A.Z. Beisenov, D.T. Shashenov. Tasmola Kurgans in Aiyrtas Valley in Central Kazakhstan

Таблица 1. Данные погребального обряда раскопанных курганов могильников Айыртас (A1), Айыртас-2 (А2) и Естек (Е), Центральный Казахстан

Table 1. The data of the funeral rite of the excavated mounds of the burial sites Aiyrtas (A1), Aiyrtas-2 (A2) and Estek (E), Central Kazakhstan

\begin{tabular}{|l|c|c|c|c|c|c|c|}
\hline $\begin{array}{c}\text { Могильник, } \\
\text { курган }\end{array}$ & $\begin{array}{c}\text { Диаметр } \\
\text { насыпи, м }\end{array}$ & $\begin{array}{c}\text { Высота } \\
\text { насыпи, м }\end{array}$ & $\begin{array}{c}\text { Размеры } \\
\text { могилы, м }\end{array}$ & $\begin{array}{c}\text { Глубина } \\
\text { могилы, м }\end{array}$ & $\begin{array}{c}\text { Ориентировка } \\
\text { могилы }\end{array}$ & $\begin{array}{c}\text { Ориентировка } \\
\text { погребенного }\end{array}$ & $\begin{array}{c}\text { Положение } \\
\text { погребенного }\end{array}$ \\
\hline A1, к. 1 & 13 & 0,8 & $2,6 \times 2,1$ & 1,1 & С3-ЮВ & С3 & Вытянуто на спине \\
\hline А1, к. 2 & 8 & $0,3 ?$ & $1,8 \times 1,3$ & 0,8 & С3-ЮВ & - & - \\
\hline А2, к. 5 & 5 & 0,2 & $2,1 \times 1,3$ & 0,9 & СВ-Ю3 & СВ & Вытянуто на спине \\
\hline А2, к. 6 & 9 & 0,5 & $1,5 \times 1$ & 1,2 & С3-ЮВ & С3 & Вытянуто на спине \\
\hline А2, к. 8 & 9 & 1,2 & $2,3 \times 1,1$ & 1,1 & С3-ЮВ & С3 & Вытянуто на спине \\
\hline А2, к. 9 & 10 & - & $2,5 \times 1,7$ & 0,7 & С3-ЮВ & С3 & Вытянуто на спине \\
\hline Е, к. 1 & 10 & 0,3 & $2,5 \times 1,3$ & 1 & 3-В & - & - \\
\hline Е, к. 2 & 11 & 0,3 & $2,2 \times 1,5$ & 1,4 & С3-ЮВ & С3 & Вытянуто на спине \\
\hline
\end{tabular}
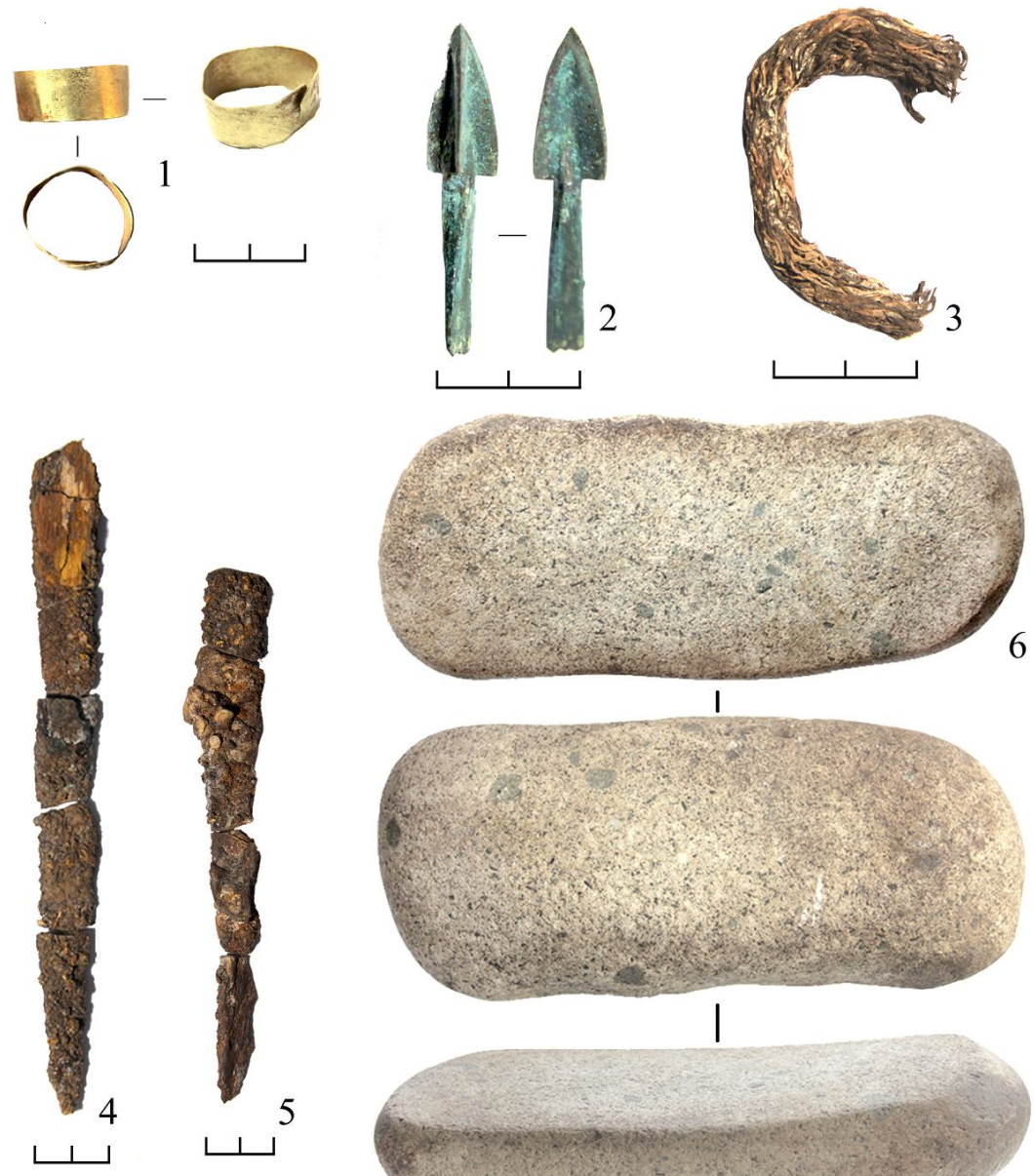

I

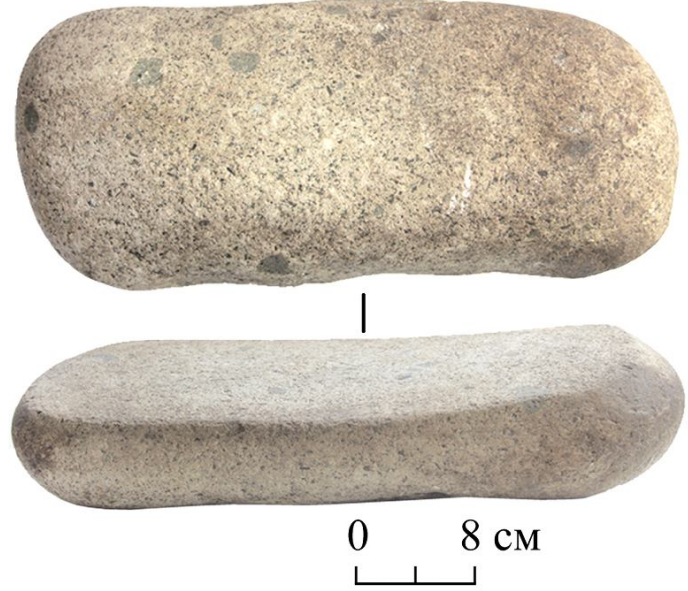

Рис. 2. Находки из погребений:

1 - золотое кольцо; 2 - бронзовый наконечник стрелы; 3 - фрагмент шерстяного аркана; 4, 5 - железные ножи; 6 - каменная зернотерка

(1-3 - могильник Айыртас-1, кург. 1; 4-5 - могильник Айыртас-2, кург. 5; 6 - могильник Айыртас-2, кург. 9)

Fig. 2. Finds from burials:

1 - a gold ring; 2 - bronze arrowhead; 3 - a fragment of wool rope;

4, 5 - iron knives; 6 - stone tool for grinding grain

(1-3 - Aiyrtas-1 kurgan cemetery, kurgan 1; 4-5 - Aiyrtas-2 kurgan cemetery, kurgan 5;

6 - Aiyrtas-2 kurgan cemetery, kurgan 9) 

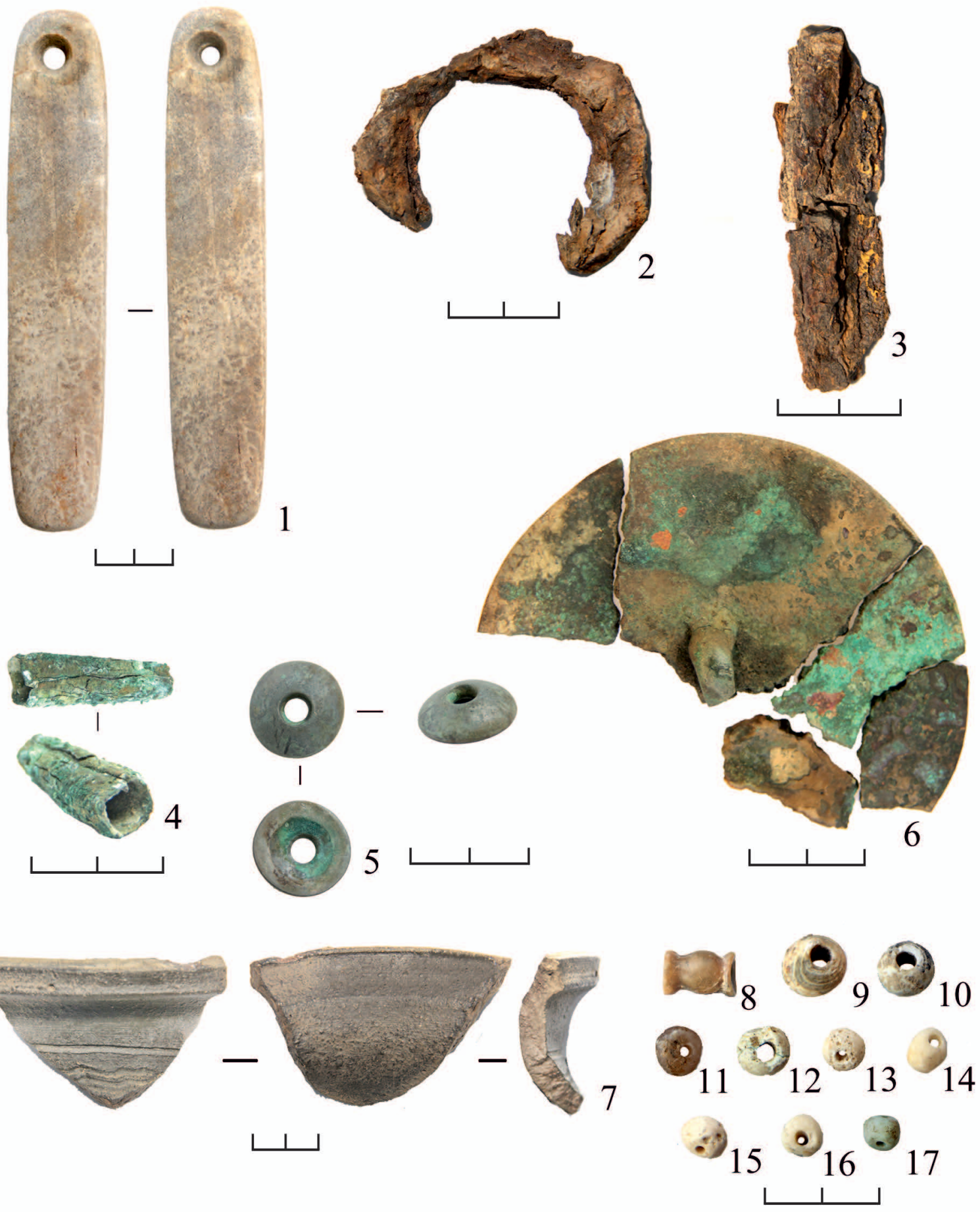

Рис. 3. Находки из погребений:

1 - каменное точило; 2 - железное кольцо; 3 - фрагмент железного кинжала; 4 - бронзовое изделие;

5 - бронзовая ворворка; 6 - бронзовое зеркало; 7 - фрагмент керамики; $8-17$ - каменные бусы

(1-3, 5 - могильник Айыртас-2, кург. 9; 4 - могильник Айыртас-2, кург. 5; 6-17 - могильник Естек, кург. 2)

Fig. 3. Finds from burials:

1 - stone sharpener; 2 - iron ring; 3 - fragment of iron dagger;

4 - bronze product; 5 - bronze detail; 6 - bronze mirror; 7 - fragment of ceramics; $8-17$ - stone beads

(1-3, 5 - Aiyrtas-2 kurgan cemetery, kurgan 9; 4 - Aiyrtas-2 kurgan cemetery, kurgan 5;

6-17 - Estek kurgan cemetery, kurgan 2) 
A.Z. Beisenov, D.T. Shashenov. Tasmola Kurgans in Aiyrtas Valley in Central Kazakhstan

Таблица 2. Бусы из кург. 2 могильника Естек, Центральный Казахстан (д.т.н. В.С.Портнов, Карагандинский политехнический университет, г. Караганда, Казахстан)

Table 2. Beads from the mound 2 of Estek burial ground, Central Kazakhstan

(Doctor of Technical Sciences V.S. Portnov, Karaganda Polytechnic University, Karaganda, Kazakhstan)

\begin{tabular}{|l|l|}
\hline \multicolumn{1}{|c|}{ Материал } & \multicolumn{1}{|c|}{ Количество, форма, размеры бусинок, рисунок } \\
\hline Опал & $\begin{array}{l}\text { 2, коричневая, бочковидная, длина 13 мм, диаметр в середине } \\
\text { 8 мм, диаметр отверстия 3 мм (рис. 3,8) }\end{array}$ \\
\hline Ракушечник & $\begin{array}{l}\text { 2, светло-коричневая, округлая, диаметр 13 мм, диаметр } \\
\text { отверстия 4 мм (рис. 3,9) }\end{array}$ \\
\hline Ракушечник & $\begin{array}{l}\text { светло-коричневых, синеватых оттенков, округлая, диаметр } \\
10 \text { мм, диаметр отверстия 4 мм (рис. 3,10) }\end{array}$ \\
\hline Опал (коричневый) & $\begin{array}{l}\text { коричневая, формы, плоская округлая, диаметр 9 мм, толщина } \\
\text { 5 мм, диаметр отверстия 2 мм (рис. 3,11) }\end{array}$ \\
\hline Мергель (зеленый) & $\begin{array}{l}\text { 1, светло-синих оттенков, округлая, диаметр 6 мм, диаметр } \\
\text { отверстия 2 мм (рис. 3,17) }\end{array}$ \\
\hline Известняк & $\begin{array}{l}\text { 5, светлая, округлая, диаметр 10 мм, диаметр отверстия } 4 \text { мм } \\
\text { (рис. 3,12) }\end{array}$ \\
\hline Известняк & $\begin{array}{l}\text { светлая, округлая, диаметр } 8 \text { мм, диаметр отверстия 2 мм } \\
\text { (рис. 3,13) }\end{array}$ \\
\hline Известняк & $\begin{array}{l}\text { светлая, округлая, диаметр 7 мм, диаметр отверстия 3 мм } \\
\text { (рис. 3,14) }\end{array}$ \\
\hline Известняк & $\begin{array}{l}\text { светлая, округлая, диаметр } 8 \text { мм, диаметр отверстия } 2 \text { мм } \\
\text { (рис. 3,15) }\end{array}$ \\
\hline Известняк & $\begin{array}{l}\text { светлая, плоская округлая, диаметр } 8 \text { мм, толщина } 5 \text { мм, } \\
\text { диаметр отверстия 2 мм (рис. 3,16) }\end{array}$ \\
\hline
\end{tabular}




\section{СПИСОК ЛИТЕРАТУРЫ}

Бейсенов А. 3., 1995. К вопросу о выделении памятников коргантасского типа в Восточной Сарыарке (вторая половина - конец І тысячелетия до н.э.) // Этнокультурные процессы на территории Казахстана (древность, средневековье, современность). Алматы : Санат. С. 55-61.

Бейсенов А. 3., 2014. О памятниках карамолинского типа в Восточной Сарыарке (вторая половина I тыс. до н.э.) // Вестник Новосибирского государственного университета. История. Филология. Т. 13, вып. 7. С. 68-79.

Бейсенов А. 3., 2015. Околокурганные жертвенники как разновидность памятников тасмолинской культуры // Вестник Томского государственного университета. История. № 4 (36). C. 96-104. DOI: https:// doi.org/10.17223/19988613/36/16.

Бейсенов А. 3., 2016. Дромосные курганы сакской эпохи на реке Жарлы (Центральный Казахстан) // Самарский научный вестник. № 3 (16). С. 77-86.

Бейсенов А. 3., 2017. Коргантасские погребения в Центральном Казахстане //Актуальные вопросы археологии и этнологии Центральной Азии : материалы II Междунар. науч. конф., посвящ. 80-летию д.и.н., проф. П. Б. Коновалова (г. Улан-Удэ, 4-6 декабря 2017 г.). Улан-Удэ : Изд-во БНЦ СО РАН. С. 103-108.

Бейсенов А. 3., Дуйсенбай Д. Б., 2015а. Исследование нового памятника коргантасского времени на могильнике Байке-2 (Центральный Казахстан) // Археология Западной Сибири и Алтая: опыт междисциплинарных исследований. Барнаул : Изд-во АГУ. С. 298-301.

Бейсенов А. 3., Дуйсенбай Д. Б., 2015б. Исследования на могильнике Байке-2 // Сакская культура Сарыарки в контексте изучения этносоциокультурных процессов Степной Евразии : сб. науч. ст., посвящ. памяти археолога К.А. Акишева. Алматы : НИЦИА «Бегазы-Тасмола». С. 71-76.

Бейсенов А. 3., Исмагулова А. О., Китов Е. П., Китова А. О., 2015. Население Центрального Казахстана в I тыс. до н.э. Алматы : Институг археологии. $188 \mathrm{c}$.

Бейсенов А. 3., Шульга П. И., Ломан В. Г., 2017. Поселения сакской эпохи. Алматы : НИЦИА «Бегазы-Тасмола». $208 \mathrm{c}$.

Кадырбаев М. К., 1958. О некоторых памятниках ранних кочевников Центрального Казахстана // Известия АН КазСС. История, археология и этнография. Вып. 1 (6). С. 95-104.

Кадырбаев М. К., 1959. Памятники ранних кочевников Центрального Казахстана // Труды Института ИАЭ АНКазССР : в 15 т. Т. 7. Алма-Ата : Наука. С. 162-203.

Кадырбаев М. К., 1966. Памятники тасмолинской культуры // Древняя культура Центрального Казахстана. Алма-Ата : Наука. С. 303-433.

Караганда. Карагандинская область : энциклопедия, 1986. Алма-Ата : Казахская советская энциклопедия. 608 с., илл. 713, карт 15.

Кирюшин Ю. Ф., Тишкин А. А., 1997. Скифская эпоха Горного Алтая. Часть І. Культура населения в раннескифское время. Барнаул : АГУ. 232 с.

Китов Е. П., Бейсенов А. 3., 2015. Первые краниологические данные памятников коргантасского типа Центрального Казахстана // Вестник Челябинского государственного университета. История. Вып. 64. № 14 (369). C. 16-28.

Кызласов Л. Р., 1977. Уюкский курган Аржан и вопрос происхождения сакской культуры // Советская археология. № 2. С. 69-86.

Кукушкин И. А., Ломан В. Г., 2013. Курган Борлы //Археологические исследования степной Евразии : сб. науч. ст. Караганда : TENGRI Ltd. C. 192-195.

История Каркаралы в документах и материалах. Т. 2. Каркаралинский внешний округ, 2009. Алматы : Институт археологии им. А.Х. Маргулана : НИЦИА «Бегазы-Тасмола». 508 с.

Маргулан А. Х., 1979. Бегазы-дандыбаевская культура Центрального Казахстана. Алма-Ата : Наука. 335 с.

Молодин В. И., Бородовский А. П. 1994. Каменные ручные жернова в древней погребальной обрядности Западной Сибири // Altaica. Новосибирск : Изд-во ИАЭТ СО РАН. С. 72-79.

Наглер А., 2000. О жерновах в погребальных памятниках степей Евразии // Археология, этнография и антропология Евразии. № 2 (2). С. 107-111.

Савинов Д. Г., 1994. Оленные камни в культуре кочевников Евразии. СПб. : Изд-во СПбГУ. 208 с. 
Савинов Д. Г., 2002. Ранние кочевники Верхнего Енисея. Археологические культуры и культурогенез. СПб. : СПбГУ. $204 \mathrm{c.}$

Тетерин Ю. В., Митько О. А., 2014. Курганы раннескифского времени могильника Ак-Даг І в Тыве // Вестник Новосибирского государственного университета. Серия: История, филология. Т. 13, вып. 5. С. 135-145.

Ткачев А. А., Волошин В. С., 2011. Одиночные захоронения раннего железного века бассейна р. Нуры // Вестник археологии, антропологии и этнографии. № 1 (14). С. 80-86.

Хабдулина М. К., 2017. Итоги изучения улубай-тасмолинской культуры Северной Сарыарки // Казахстан в сакскую эпоху. Алматы : Институт археологии : НИЦ истории и археологии Бегазы-Тасмола. С. 35-58.

Шульга П. И., 2015. О захоронениях коргантасского типа // Сакская культура Сарыарки в контексте изучения этносоциокультурных процессов степной Евразии. Алматы : НИЦИА «Бегазы-Тасмола». С. 405-418.

Beisenov A. Z., Svyatko S. V., Kassenalin A. E., Zhambulatov K. A., Duisenbai D., Reimer P. J., 2016. First Radiocarbon Chronology for the Early Iron Age Sites of Central Kazakhstan (Tasmola Culture and Korgantas Period) // Radiocarbon. Vol. 58, iss. 1. P. 179-191. DOI: https://doi.org/10.1017/RDC.2015.18.

\section{REFERENCES}

Beisenov A.Z., 1995. K voprosu o vydelenii pamiyatnikov korgantasskogo tipa v Vostocnoi Saryarke (vtoraiya polovina - konets I tysiyatcheletiya do n.e.) [On the Issue of Identifying Korgantas-Type Monuments in East Saryarka (the Second Half - the End of the $\mathrm{I}^{\mathrm{st}}$ Millennium BC)]. Etnokulturnye protsessy na territorii Kasahstana (drevnost, srednevekovie, sovrevennost) [Ethnocultural Processes on the Territory of Kazakhstan (Antiquity, the Middle Ages, Modernity)]. Almaty, Sanat Publ., pp. 55-61.

Beisenov A.Z., 2014. O pamyatnikakh karamolinskogo tipa v Vostochnoy Saryarce (vtoraya polovina I tys. do n.e.) [About Sites of Karamola Type in Eatern Saryarka (Second Half of I Millennium BC). Vestnik Novosibirskogo Gosudarstvennogo Universiteta. Istoriya. Philologiya [Novosibirsk State University Bulletin. Series: History and Philology], vol. 13, iss. 7, pp. 68-79.

Beisenov A.Z., 2015. Okolokurgannye dhertvenniki kak rasnovidnosnt' pamiyatnikov tasmolinskoi kultury [Sacrificial Constructions Near Kurgans as Type of Tasmola Culture Monuments]. Vestnik Tomskogo gosudarstvennogo universiteta. Istoriya [Bulletin of Tomsk State University. History], no. 4 (36), pp. 96-104. DOI: https://doi.org /10.17223/19988613/36/16.

Beisenov A.Z., 2016. Dromosnye kurgany na reke Jarly (Tsentralnyi Kasakhstan) [Dromos Kurgans of the Saka Time on the Zharly River (Central Kazakhstan)]. Samarskiy nauchnyy vestnik [Samara Journal of Science], no. 3 (16), pp. 77-86.

Beisenov A.Z., 2017. Korgantasskie pogrebeniya v Central'nom Kazahstane [Korgantas Burials in Central Kazakhstan]. Aktual'nye voprosy arheologii i etnologii Central'noy Azii: materialy II Mezhdunar. nauch. konf., posvyashch. 80-letiyu d.i.n., prof. P.B. Konovalova (g. Ulan-Ude, 4-6 dekabrya 2017 g.) [Actual Issues of Archeology and Ethnology of Central Asia. Materials of the II International Scientific Conference Dedicated to the $80^{\text {th }}$ Anniversary of Doctor of Historical Sciences, prof. P.B. Konovalov (Ulan-Ude, December 4-6, 2017)]. Ulan-Ude, BSC SB RAS, pp. 103-108.

Beisenov A.Z., Duisenbay D.B., 2015a. Issledovanie novogo pamyatnika korgantasskogo vremeni na mogil'nike Bayke-2 (Central'nyy Kazahstan) [Investigation of the New Korgantas Time Monument at the Baike-2 Burial Ground (Central Kazakhstan)]. Arheologiya Zapadnoy Sibiri i Altaya: opyt mezhdisciplinarnyh issledovaniy [Archeology of Western Siberia and Altai: Experience of Interdisciplinary Research]. Barnaul, Altai State University, pp. 298-301.

Beisenov A.Z., Duisenbay D.B., 2015b. Issledovaniya na mogil'nike Bayke-2 [Studies at the Baike-2 Burial Ground]. Sakskaya kul'tura Saryarki v kontekste izucheniya etnosociokul'turnyh processov Ctepnoy Evrazii: sb. nauch. st., posvyashch. pamyati arheologa K.A. Akisheva [Saka Culture of Saryarka in the Context of the Study of Ethnosocial and Cultural Processes of Steppe Eurasia. Collection of Scientific Articles Dedicated to the Memory of Archaeologist K.A. Akishev]. Almaty, NICIA «Begazy-Tasmola», pp. 71-76.

Beisenov A.Z., Ismagulova A.O., Kitov E.P., Kitova A.O., 2015. Naselenie Central'nogo Kazahstana v I tys. do n.e. [The Population of Central Kazakhstan in I Millennium BC]. Almaty, Institute of Archeology. 188 p.

Beisenov A.Z., Shulga P.I., Loman V.G., 2017. Poseleniya sakskoy epohi [Settlements of the Saka Era]. Almaty, NICIA «Begazy-Tasmola». $208 \mathrm{p}$. 
Kadyrbaev M. K, 1958. O nekotoryh pamyatnikah rannih kochevnikov Central'nogo Kazahstana [About Some Monuments of the Early Nomads of Central Kazakhstan]. Izvestiya AN KazSS. Istoriya, arheologiya $i$ etnografiya [News of the Academy of Sciences of the Kazakh SSR. History, Archeology and Ethnography], iss. 1 (6), pp. 95-104.

Kadyrbaev M.K, 1959. Pamyatniki rannih kochevnikov Central'nogo Kazahstana [Monuments of the Early Nomads of Central Kazakhstan]. Trudy Instituta IAE ANKazSSR: $v 15 t$. [Proceedings of the Institute of IAE of the Academy of Sciences of the Kazakh SSR. In 15 vols.]. Alma-Ata, Nauka Publ., vol. 7, pp. 162-203.

Kadyrbaev M.K, 1966. Pamyatniki tasmolinskoy kul'tury [Monuments of Tasmola Culture]. Drevnyaya kul'tura Central'nogo Kazahstana [The Ancient Culture of Central Kazakhstan]. Alma-Ata, Nauka Publ., pp. 303-433.

Karaganda. Karagandinskaya oblast': Enciklopediya [Karaganda. Karaganda Region: Encyclopedia], 1986. AlmaAta, Ch. ed. Kazakh Soviet Encyclopedia. 608 p., Ill. 713, cards 15.

Kiryushin Yu.F., Tishkin A.A., 1997. Skifskaya epoha Gornogo Altaya. Chast'I. Kul tura naseleniya v ranneskifskoe vremya [Scythian Era of Mountain Altai. Part I. Culture of the Population in the Early Scythian Time]. Barnaul, Altai State University. 232 p.

Kitov E.P, Beisenov A.Z, 2015. Pervye kraniologicheskie dannye pamyatnikov korgantasskogo tipa Central'nogo Kazahstana [The First Craniological Data of the Korgantas-Type Monuments of Central Kazakhstan]. Vestnik Chelyabinskogo gosudarstvennogo universiteta [Bulletin of the Chelyabinsk State University], no. 14 (369), history, iss. 64, pp. 16-28.

Kyzlasov L. R., 1977. Uyukskiy kurgan Arzhan i vopros proiskhozhdeniya sakskoy kul'tury [Uyuk Barrow Arzhan and the Issue of the Origin of Saki Culture]. Sovetskaya arheologiya [Soviet Archeology], no. 2, pp. 69-86.

Kukushkin I.A., Loman V.G., 2013. Kurgan Borly [Borly Barrow]. Arheologicheskie issledovaniya stepnoy Evrazii: sb. nauch. st. [Archaeological Studies of Steppe Eurasia. Collection of Scientific Articles]. Karaganda, TENGRI Ltd Publ., pp. 192-195.

Istoriya Karkaraly v dokumentah i materialah. T. 2. Karkaralinskiy vneshniy okrug [History of Karkaraly in Documents and Materials. Volume 2. Karkaraly External District], 2009. Almaty, Institute of Archeology named after A.Kh. Margulan; NICIA «Begazy-Tasmola». 508 p.

Margulan A.Kh., 1979. Begazy-dandybaevskaya kul'tura Central'nogo Kazahstana [Begazy-Dandybaev Culture of Central Kazakhstan]. Alma-Ata, Nauka Publ. 335 p.

Molodin V.I., Borodovsky A.P., 1994. Kamennye ruchnye zhernova v drevney pogrebal'noy obryadnosti Zapadnoy Sibiri [Stone Hand Millstones in the Ancient Funeral Ritual of Western Siberia]. Altaica. Novosibirsk, IAET SB RAS, pp. 72-79.

Nagler A., 2000. O zhernovah v pogrebal'nyh pamyatnikah stepey Evrazii [About Millstones in Burial Monuments of the Steppes of Eurasia]. Arheologiya, etnografiya $i$ antropologiya Evrazii [Archeology, Ethnography and Anthropology of Eurasia], no. 2 (2), pp. 107-111.

Savinov D.G, 1994. Olennye kamni v kul'ture kochevnikov Evrazii [Deer stones in the culture of the nomads of Eurasia]. Saint Petersburg, Saint Petersburg University. 208 p.

Savinov D.G, 2002. Rannie kochevniki Verhnego Eniseya. Arheologicheskie kul'tury i kul'turogenez [Early Nomads of the Upper Yenisei. Archaeological Cultures and Cultural Cenesis]. Saint Petersburg, Saint Petersburg University. 204 p.

Teterin Yu.V., Mitko O.A., 2014. Kurgany ranneskifskogo vremeni mogil'nika Ak-Dag I v Tyve [Early Scythian Mounds of the Ak-Dag I Burial Ground in Tyva]. Vestnik Novosibirskogo gosudarstvennogo universiteta. Seriya: Istoriya, filologiya [Novosibirsk State University Bulletin. Series: History and Philology], vol. 13, iss. 5, pp. 135-145.

Tkachev A.A., Voloshin V.S., 2011. Odinochnye zahoroneniya rannego zheleznogo veka basseyna r. Nury [Single Burials of the Early Iron Age of the River Basin Nury]. Vestnik arheologii, antropologii i etnografii [Bulletin of Archeology, Anthropology and Ethnography], no. 1 (14), pp. 80-86.

Khabdulina M.K, 2017. Itogi izucheniya ulubay-tasmolinskoy kul'tury Severnoy Saryarki [The Results of the Study of the Ulubay-Tasmolinskaya Culture of the Northern Saryarka]. Kazakhstan v sakskuyu epokhu [Kazakhstan in the Saka Era]. Almaty, Institute of Archeology; NICIA «Begazy-Tasmola», pp. 35-58.

Shulga P.I., 2015. O zakhoroneniyakh korgantasskogo tipa [On the Korgantas Type Graves]. Sakskaya kul tura Saryarki v kontekste izucheniya etnosociokul'turnyh processov stepnoy Evrazii [Saka Culture of Saryarka 
A.Z. Beisenov, D.T. Shashenov. Tasmola Kurgans in Aiyrtas Valley in Central Kazakhstan

in the Context of the Study of Ethnosocial and Cultural Processes of Steppe Eurasia]. Almaty, NICIA «BegazyTasmola», pp. 405-418.

Beisenov A.Z., Svyatko S.V., Kassenalin A.E., Zhambulatov K.A., Duisenbai D., Reimer P.J., 2016. First Radiocarbon Chronology for the Early Iron Age Sites of Central Kazakhstan (Tasmola Culture and Korgantas Period), Radiocarbon, vol. 58, iss. 1, pp. 179-191. DOI: https://doi.org/10.1017/RDC.2015.18.

\section{Information About the Authors}

Arman Z. Beisenov, Candidate of Sciences (History), Director, Research Center for the History and Archeology of Begazy-Tasmola, Zhambul St., bld. 175, kv. 61, 050008 Almaty, Republic of Kazakhstan, azbeisenov@mail.ru, https://orcid.org/0000-0003-2524-264X

Darkhan T. Shashenov, Master of Sciences (Human), Senior Researcher, Department of General History, Archeology and Ethnography, Karaganda Regional Museum of Local History, Erubaev St., 38, 100008 Karaganda, Republic of Kazakhstan, darkhan_57@mail.ru, https://orcid.org/0000-0002-4791-4673

\section{Информация об авторах}

Арман Зияденович Бейсенов, кандидат исторических наук, директор, Научно-исследовательский центр истории и археологии Бегазы-Тасмола, ул. Жамбула, д. 175, кв. 61, 050008 г. Алматы, Республика Казахстан, azbeisenov@mail.ru, https://orcid.org/0000-0003-2524-264X

Дархан Тастемирович Шашенов, магистр гуманитарных наук, старший научный сотрудник отдела общей истории, археологии и этнографии, Карагандинский областной историко-краеведческий музей, ул. Ерубаева, 38, 100008 г. Караганда, Республика Казахстан, darkhan_57@mail.ru, https://orcid.org/0000-0002-4791-4673 